\title{
A babá de Freud e outras babás*
}

\author{
Mariza Corrêa**
}

\begin{abstract}
Resumo
Depois da publicação das cartas de Freud a Fliess a literatura psicanalítica começou a prestar atenção à babá de Freud e, por consequência, à importância da babá na família ideal dessa literatura. Incluída, na prática, nos modelos explicativos de análise da família burguesa desde o século dezenove, a babá, ainda demasiado presente nas famílias de classe média e alta no Brasil, foi excluída da teoria analítica e continua a por em questão o triângulo "papai-mamãe-filho".
\end{abstract}

Palavras-chave: Babás/Governantas/Criadas, Freud, Trabalho Doméstico, Migração de Mulheres.

\footnotetext{
" Recebido para publicação em maio de 2007, aceito em agosto de 2007. Agradeço a Adriana Piscitelli, Claudia Fonseca, Claudia Lemos, Heloisa Pontes, Henrique D. Dentzien, Iara Beleli, Julio Assis Simões, Lilia Schwarcz e Sandra Koutsoukos pela leitura de versões preliminares deste texto e por suas sugestões e comentários. Agradeço também aos meus alunos do ano de 2007, com quem pude discutir essas idéias de maneira tão agradável.

** Antropóloga, Pesquisadora do Núcleo de Estudos de Gênero - Pagu/ Unicamp.correa.mariza@uol.com.br
}

cadernos pagu (29), julho-dezembro de 2007:61-90. 
A babá de Freud e outras babás

Freud's Nanny and Other Nannies

\begin{abstract}
The Freud-Fliess letters attracted attention to Freud's nanny and also to the role played by nannies in the ideal family of psychoanalytic theory. Included in the models that explained the bourgeois family since the nineteenth century, but excluded by analytic theory, the nanny, ever present in Brazilian upper-class families, still poses a question to the 'father-mother-infant' triangle.
\end{abstract}

Key Words: Nannies-Governesses-Maids, Freud, Domestic Work, Female Migration. 
Mariza Corrêa

Pobre gente! Nem sequer pode conservar o nome.

Freud

Em meados do século vinte, precisamente em 1964 e 1965, duas babás, encarnadas pela mesma atriz, Julie Andrews, fizeram sucesso no cinema - e, antes ou depois, em vários palcos do mundo. Uma delas era inglesa, a outra austríaca. ${ }^{1}$ As babás inglesas eram então há muito tempo famosas, tanto no seu país, como no exterior: vários memorialistas e romancistas do século 19 as mencionam como fontes de prazer, ou, com freqüência, de desprazer. ${ }^{2}$ Já as babás austríacas eram menos conhecidas até que foram postas na cena analítica por Sigmund Freud. ${ }^{3}$ Quase todas

1 Mary Poppins, produzida pela Disney e dirigida por Robert Stevenson, filme lançado em 1964, e The sound of music (A noviça rebelde), dirigido por Robert Wise, lançado em 1965. Os dois roteiros se originaram de textos escritos por mulheres - Mary Poppins foi uma série de sucesso publicada na Inglaterra entre 1934 e 1988, pela autora australiana Pamela Lyndon Travers (ou P. L. Travers, evocando J.K. Rowling, de Harry Potter), e The sound of music se originou da autobiografia da própria babá, Maria von Trapp. Ver Anne McLeer (2002) para uma análise sobre esses filmes como expressão das apreensões causadas pelo movimento feminista dos anos sessenta nos Estados Unidos. No momento em que escrevo há também várias séries de tevê com babás como personagens centrais - além de uma "babá do mal" no seriado infantil Padrinhos Mágicos.

2 Para exemplos de castigos terríveis impostos a eles por suas babás, rememorados por escritores ingleses, ver Yara Frateschi Vieira (1989) e Anne McClintock (1995). Esta última cita também personagens importantes, como Winston Churchill, que tinham profunda afeição por suas babás. Uma das primeiras pacientes de Freud foi uma babá inglesa e a análise de outra babá foi usada por Anna Freud (1983:cap.X) para analisar a noção de "rendição altruísta", uma forma de projeção.

${ }^{3}$ Chamo aqui de babá aquelas que na literatura sobre o século 19 são chamadas às vezes de nanny, às vezes de nurse. Estritamente, a babá (nanny) seria a pessoa encarregada da criança na primeira infância, enquanto que a nurse, ou governanta, tomaria conta dela a partir do momento em que algum tipo de ensino, principalmente para meninas (os meninos iam para a escola), era administrado em casa. Na realidade, e na ficção, ambas se confundem. Ver, por exemplo, para uma boa descrição de suas atribuições - e de seu destino quando envelheciam -, Virginia Woolf, The years. Sua irmã, Vanessa Bell, imortalizou cenas de babás e crianças em seus quadros. Sobre o contexto familiar da infância 
A babá de Freud e outras babás

as suas pacientes jovens tinham babás/governantas - algumas tinham duas, o que vai levar a um curioso desdobramento dessa personagem, seja na relação mãe-boa/babá-má, seja, numa espécie de duplicação, como babá boa/babá má. ${ }^{4}$

O interesse de Freud pelas babás começa, parece, com as análises dos casos que ficaram conhecidos na literatura sobre a história freudiana como aqueles que deram origem à "teoria da sedução" - e com a sua auto-análise. Esse interesse, no entanto, se estende para muito além dos marcos temporais de uma ou de outra, como veremos. As recentes publicações críticas, surgidas no rastro do que está sendo chamado de "Freudian wars" - as guerras freudianas, no entanto, prestaram pouquíssima atenção a esse interesse, talvez porque os autores julguem que se trata de um assunto "menor" ou "doméstico". 5 Tento argumentar aqui, com o apoio de outros autores que se dedicaram ao assunto, que se trata de um tema de grande relevância, não apenas na economia doméstica, e na economia dos afetos, do século dezenove, em Viena, e alhures no mundo que se industrializava, mas também para uma reflexão feminista no Brasil contemporâneo.

de Virginia Woolf, ver a importante pesquisa de Louise De Salvo (1989) - no caso dela o sedutor era um meio-irmão, e não a babá.

${ }^{4}$ Não penso aqui, como entendeu uma de minhas leitoras, na introjeção psicológica de objeto bom/objeto mau, como em Melanie Klein, mas na relação sociológica que se estabelecia entre babás/governantas e aqueles de quem elas cuidavam na infância ou com quem se relacionavam na adolescência - um pouco à maneira como Freud usa os dados familiares do poeta H.Heine para compreender a situação dele - no seu texto sobre os "chistes".

${ }^{5}$ Ver Catherine Meyer (2005). O menos interessante nessas guerras é o afã de desmoralizar Freud - afinal, quem se interessa por saber se ele dormiu ou não com a cunhada?; o mais interessante são os conflitos de interpretações de uma época. 
Mariza Corrêa

\section{A teoria da sedução}

Convém começar por um resumo sobre a assim chamada "teoria da sedução": em 1896 Freud publicou um artigo polêmico, no qual atribuía a causa da histeria a um trauma sexual sofrido por suas pacientes $-e$ alguns pacientes homens - desde atentados ao pudor até abusos sexuais, por parte de membros de sua família mais próxima: tios (alguns deles que, em notas posteriores, se revelaram como sendo pais), irmãos, tutores, colegas de escola, ou babás. Diz ele que o trauma era causado, "infelizmente com freqüência grande demais, [por] um parente próximo". ${ }^{6}$ Nesse artigo, ele afirmava que nos 18 casos de histeria que analisara até então (seis homens e doze mulheres), todos eles apresentavam essa etiologia, ou causa, da condição. A partir do ano seguinte, começou a duvidar dessa proposta, tendo escrito a Fliess: "Não acredito mais na minha neurótica [teoria das neuroses]". ${ }^{7}$ Apesar de ainda mencionar a teoria da sedução em outras cartas desse ano (e voltar a mencioná-la também anos depois), passou, então, a tratar dessas denúncias como sendo uma fantasia de suas pacientes. ${ }^{8}$

\footnotetext{
${ }^{6}$ Freud, A etiologia da histeria, reproduzida como apêndice $\mathrm{B}$ ao livro de Masson (1984:243). Alguns desses casos devem ser os transcritos nos Estudos sobre a histeria, de Freud e Breuer, publicado originalmente em 1895, entre eles o da governanta inglesa, Miss Lucy R. e o de Katharina - cujo sedutor, apresentado na edição original como sendo seu tio, era de fato o pai, conforme nota acrescentada por Freud em 1924. A análise de Miss Lucy é também um interessante retrato da vida das babás em Viena.

7 Carta a Fliess, na correspondência Freud-Fliess (Masson, 1986:265). A carta é de setembro, mas em dezembro ele ainda se mostrava indeciso ao anotar um fragmento de caso e um "novo lema": "Que fizeram com você, pobre criança?", citando Goethe (Id. ib:290). Ver também as cartas de 1898 e de 1899 nas quais essa indecisão aparece.

8 A passagem do trauma da sedução para a fantasia de sedução é objeto de controvérsias na literatura psicanalítica, mas ver os ensaios do próprio Freud em 1905 e 1906. Ver também a revisão de Ahbel-Rappe (2006).
} 
A babá de Freud e outras babás

Vários autores contemporâneos trataram do tema da babá nos textos freudianos, mas quase sempre interessados na babá dele. Sua babá, da qual até o nome está em discussão hoje, teria sido uma tcheca, católica, que o levava à missa e o reprovava por ele não ser capaz de nada. ${ }^{9}$ Diz ele:

O sonho de hoje trouxe o seguinte, sob os mais estranhos disfarces: ela era minha mestra em assuntos sexuais $e$ reclamava por eu ser desajeitado e incapaz de fazer qualquer coisa. [E, um pouco mais adiante] ela me lavava numa água avermelhada em que se havia banhado antes. ${ }^{10}$

Contando que a babá o fazia furtar dinheiro e dar a ela, Freud interpreta o sonho como sendo uma reprovação por estar cobrando de pacientes por seu mau tratamento, assim como "a velha recebia dinheiro de mim pelo mau tratamento que me dispensava". Na carta seguinte, de 15 de outubro, Freud relata o que sua mãe lhe contou da babá. Ao perguntar se lembrava dela, obteve a seguinte resposta:

"É claro", disse ela, "uma pessoa mais velha, muito esperta, que estava sempre levando você para alguma igreja: quando voltava para casa, você fazia sermões e nos dizia tudo sobre Deus Todo-Poderoso. Durante meu resguardo de Anna (dois anos e meio mais nova), descobriu-se que

9 Didier Anzieu (1989) cita o nome mais freqüentemente evocado na literatura, o de Monika Zajic, mas menciona também a possibilidade de Resi Wittek ou Magdalena Kabet terem sido as babás de Freud. Sander Gilman (1993), opta por Teresa "Resi" Wittek. Jones (1974) menciona a relação hostil entre tchecos e judeus na região, na época, incluindo movimentos dos tchecos, que eram maioria, contra os judeus.

${ }^{10}$ Carta a Fliess, de 4 de outubro de 1897 (Masson, 1986:270). Essa carta, que começou a ser escrita no dia 3 de outubro, parece ter marcado o abandono, por Freud, da idéia de uma sedução feita por alguém da família: ele explicitamente exclui seu pai de qualquer responsabilidade sedutora ("meu velho não desempenha nenhum papel ativo em meu caso, mas [que], sem dúvida, fiz uma inferência sobre ele, por analogia, a partir de mim mesmo" [Id. ib.:269]). 
Mariza Corrêa

ela era ladra e todos os reluzentes kreuzers e zehners [moedas] novos $e$ todos os brinquedos que tinham sido dados a você foram encontrados em poder dela. Seu irmão Phillip foi pessoalmente buscar um policial; ela pegou dez meses de cadeia" (Masson, 1986:272).

Não interessa aqui discutir o fato de que Freud usou a lembrança de sua mãe para reforçar a interpretação anterior que fez do sonho - no qual ele roubava - nem o fato, sublinhado por alguns analistas de que ele se identificava com ela ("eu=ela"), e sim o fato de que parece que é com a auto-análise que a figura da babá passa a ser uma figura maligna ou, na melhor das hipóteses, ambígua. $^{11}$

De fato, ainda que as babás já tivessem aparecido em várias cartas desse mesmo ano como sedutoras, elas pareciam estar mais ligadas às perversões dos pais em relação a elas - ou às criadas da casa, muitas vezes dublês de babás - do que às perversões delas em relação aos filhos, ainda que essas cenas estivessem presentes no seu texto de $1896 .{ }^{12}$ Suas preocupações incluíam também as babás de sua família. Numa nota à carta de 14 de novembro de 1897, por exemplo, cita a babá de um de seus filhos como castradora, ao registrar que ele perdera o segundo dente: "De

${ }^{11}$ Ver Didier Anzieu para uma análise detalhada desse sonho - e a citação de outros analistas que apontam a possibilidade de Freud ter sido batizado pela babá e a água visualizada no sonho ser a água do batismo. Anzieu (1989:143, 145) também especula sobre se o fato de Freud ter tido duas mães seria a razão de seu interesse por grandes personagens que também tiveram duas mães: Édipo, Moisés, Leonardo da Vinci. Sander Gilman (1993) fala do medo corrente entre os judeus vienenses, e das fantasias associadas a ele, do batismo de crianças judias por babás católicas.

${ }^{12}$ Ver, por exemplo, Masson (1986:219, 220, 224, 242), para cenas de babás seduzidas ou sedutoras. Em 2 de maio de 1897, Freud falava da "sublimação dessas jovens nas fantasias" e de "algumas acusações altamente improváveis contra outras pessoas [que] ficam contidas nas fantasias", concluindo que: "Há uma trágica justiça no fato de que o rebaixamento do chefe da família diante de uma criada da casa é expiado através da auto-degradação de sua filha" (Id. ib.:242, ênfase adicional). 
A babá de Freud e outras babás

fato, o primeiro foi arrancado na noite de 9 de novembro pela babá; talvez tivesse durado até o dia 10" (Id. ib.:282, ênfase adicional). Sobre outro filho, que costumava se machucar repetidamente, dirá mais tarde, em 1899: "Atribuo isso a uma ligeira histeria. Ele foi o único a quem a antiga babá tratou mal" (Id. ib.:368). E, numa observação sobre um texto literário, se pergunta de onde vem o material para se criar o romance familiar -

adultério, filhos ilegítimos e coisas semelhantes? Em geral [d]os círculos sociais inferiores das criadas. Essas coisas são tão comuns entre elas que nunca nos falta material, e são especialmente propensas a ocorrer quando a própria sedutora foi uma empregada/da casa/. Em todas as análises, portanto, ouve-se duas vezes a mesma história: uma vez como fantasia sobre a mãe; a segunda como lembrança real da criada (Id. ib.:318, ênfase adicional).

Na carta em que rememorava sua babá, Freud fizera exatamente isso: acoplara sua lembrança da velha criada à memória de uma viagem na qual teria visto sua mãe nua. ${ }^{13}$

As babás, $e$ as criadas em geral, são de fato onipresentes no romance familiar dos círculos de Freud: o menino Hans, que tinha fobia por cavalos, cavalga a empregada e a intima a tirar a roupa; o "homem dos lobos", como Freud, também tivera uma babá camponesa, que lhe contava histórias religiosas; Dora tinha duas governantas, uma da qual gostava, outra que abominava - além do fato de a babá das crianças da família $\mathrm{K}$ ter sido seduzida pelo

\footnotetext{
13 "Só posso esclarecer que [...], em meu caso, o 'originador primordial' foi uma mulher feia e idosa, porém esperta, que muito me ensinou sobre Deus TodoPoderoso $e$ o inferno e que infundiu em mim uma opinião elevada sobre minhas próprias aptidões; que, mais tarde (entre dois anos e dois anos e meio), minha libido voltada para a matrem foi despertada, a saber, por ocasião de uma viagem com ela de Leipzig a Viena, durante a qual devemos ter passado a noite juntos e devo ter tido oportunidade de vê-la nudam [...]". Anzieu (1989:432) data essa viagem de quando Freud tinha quatro anos.
} 
dono da casa; Anna O. também gostava de uma governanta e detestava outra - e Anna Freud também teve uma babá católica, a quem amava. A filha mais velha de Freud, Mathilde, teve uma ama de leite, raramente mencionada, e a família Freud manteve relações com sua família durante muitos anos. ${ }^{14}$

\section{Seduções da teoria ${ }^{15}$}

O primeiro a ter tratado extensamente do tema parece ter sido Jim Swan, em um artigo de $1974 .{ }^{16}$ Swan cita as análises

\footnotetext{
${ }^{14} \mathrm{O}$ caso Hans está em S.Freud, Standard Edition, vol. X. Ver uma crítica feminista que atribui a fobia de Hans ao seu medo da mãe - que espancava a irmã pequena e o ameaçava de castração - no texto de Bárbara Creed (1993); o caso Dora está no vol.VII. O relato sobre a escolha do nome Dora para esta paciente está na Psicopatologia da vida cotidiana (259), de onde sai também a exclamação de Freud na epígrafe acima - ele usou o nome da babá da família de sua irmã que, por sua vez, havia sido atribuído a ela porque ela tinha o mesmo nome dessa irmã. O caso do homem dos lobos (SE, XVII) é analisado também por Ginzburg (1989), que observa como nesse texto, publicado em 1918, a teoria da sedução, supostamente abandonada em 1897, retorna à cena textual de Freud. O homem dos lobos também tinha uma babá religiosa e amorosa, além de uma governanta inglesa irascível - e embora oficialmente sua sedutora tenha sido a irmã, há pelo menos uma menção à sedução dele pela babá (AhbelRappe, 2006:182). Sobre Anna Freud, ver a biografia de Elisabeth Young-Bruehl (1992). De Anna também se dizia que tivera duas mães: a mãe Martha e a tia Minna, irmã dela, que vivia com a família, e Freud, segundo Young-Bruehl, falava com Lou Andréas-Salomé sobre a filha que partilhavam, já que ela parece ter sido a sucessora de Freud como analista de sua filha. Esse excesso de mães dedicadas a Anna precisaria ser analisado com mais vagar, já que ela se especializou na análise de crianças. Cabe também anotar que Anna, a partir de meados dos anos 20, depois das primeiras operações de Freud, tornou-se sua nurse - tomando o lugar de Martha, sua mãe - até a morte dele, em 1939, e a guardiã da herança psicanalítica da família. Anzieu (1989:143) lembra que babá em tcheco é Nana. Sobre a irmã de leite de Mathilde e sua família, ver Lou Andréas-Salomé/Anna Freud, 2006.

${ }^{15}$ A expressão é de Anzieu (1989:14): "procuro dissociar-me das duas tendências bastante prolixas dos últimos anos, uma acusando Freud pelo abandono da teoria da sedução, outra de ter-se abandonado às seduções da teoria".
} 
A babá de Freud e outras babás

pioneiras de Max Schur, de 1972, e o trabalho de Didier Anzieu, que teve várias edições, a partir de 1959. Schur foi, segundo ele, o primeiro a notar a discrepância entre a frase em alemão, que significava algo como "a primeira sedutora" - por contraste com a teoria freudiana, que postulava o pai como o primeiro sedutor - $e$ a frase da tradução inglesa, na Standard Edition, "a originária primária [de minhas dificuldades]". Esse autor notou também que a "babá" de Freud originou-se da tradução inglesa, na biografia de Ernest Jones, que usou o termo nanny para termos alemães que significavam "criada". ${ }^{17}$

Swan (1974:19) põe em cena a questão:

O que precisa ser explicado é como a teoria do complexo de Édipo dá conta dos impulsos culpados em relação à mãe, mas ignora o despertar erótico do menino pelas mãos de sua babá, particularmente levando-se em conta que sua babá obtém de Freud uma atenção muito maior do que sua mãe.

\footnotetext{
${ }^{16}$ Agradeço a Swan por ter me enviado uma cópia de seu artigo, não disponível na versão digitalizada da revista.

${ }^{17}$ Os termos parecem ser intercambiáveis - as criadas cuidavam da casa $e$ das crianças. Para uma análise da importância social do serviço doméstico, feito em geral por meninas solteiras vindas do interior do país, na França e na Inglaterra, ver o trabalho clássico de Louise Tilly e Joan Scott (1978). As autoras mostram que o avanço da industrialização não tirou as mulheres do serviço doméstico: na Inglaterra, no final do século XIX, $40 \%$ da força de trabalho feminina estava dedicada a esse tipo de serviço e dois terços dela tinha origem rural. Dois terços permaneciam solteiras. Era daí que provinham as "criadas" e "babás". Não tenho dados para a Áustria, mas a trajetória da última empregada austríaca da família Freud, Paula Fichtl, e suas atribulações (que incluíram a internação num campo de estrangeiros sem registro, na Inglaterra durante a II Guerra) como uma moça católica, de origem rural, que envelheceu no serviço doméstico, feito durante 54 anos, estão registradas no livro de Detlef Berthelsen (1996). Paula, que terminou seus dias num asilo austríaco, foi fundamental para a recuperação da organização espacial da Berggasse, 19, quando a casa de Freud se tornou um museu. Seu caso parece análogo ao de Hannah Cullwick, tratado adiante: um médico diagnosticou seus problemas de saúde em 1972, quando ela tinha 70 anos, como "obrigação neurótica de trabalho".
} 
$\mathrm{Na}$ discussão sobre as interpretações possíveis dos sonhos de Freud durante sua auto-análise, Swan vai pontuando a presença da babá como referência importante no seu desenvolvimento até chegar à conclusão de que a "circunstância notável" é a de que Freud teve, de fato, duas mães,

sua mãe real - cuja nudez ele só podia expressar em latim e sua babá, de quem ele se lembra como associada a várias experiências sexuais perturbadoras. Tendo tido duas mães, $e$ a sorte de ter a "má" e feia mãe banida de sua vida quando tinha apenas dois anos e meio, permite a Freud manter uma divisão segura entre a mãe boa e a mãe má internalizadas (Id. ib.:34).

Inconscientemente, a babá de Freud foi sua sedutora $e$ aquela que o envergonhou; sua mãe foi o puro objeto de um desejo culpado (Id., ib.:50).

A mãe boa e a babá má, ou a babá boa e a babá má, vão, a partir daí, aparecer constantemente nas análises de Freud, como se muitos de seus pacientes repetissem a sua trajetória de menino.$^{18}$ Em qualquer caso, a babá, ou governanta, como figura necessária no lar burguês vienense, está permanentemente presente - a despeito do fato, como Swan observa, de que o pai de Freud estivesse sempre à beira da miséria. Não é possível, nesse rápido resumo, fazer justiça ao trabalho de Swan, mas é preciso registrar que ele faz uma longa digressão sobre as relações sociais presentes na infância de Freud, mostrando que o Édipo burguês

\footnotetext{
${ }^{18}$ A sociologia da situação das babás foi analisada de modo condensado por Jack Goody. Procurando pela origem etimológica da palavra, Goody (1969:242) observa que, desde o final do século 16, as criadas ofereciam "serviços" em mais de um sentido, já que "nanny" era também, nos dicionários da época, sinônimo de prostituta - reforçando, assim, o sentido de "babá má". Goody não menciona a literatura psicanalítica e parece ter chegado de maneira independente à suas conclusões. Ele observa também que alguns dicionários derivam a palavra dos nomes próprios Anne, ou Anna, ou Hannah.
} 
A babá de Freud e outras babás

luta para preservar sua distinção $e$ independência daqueles de cujo trabalho corporal ele de fato depende para sua existência e status (Id. ib.:54). [E conclui afirmando] Assim, a descoberta do complexo de Édipo por Freud não apenas emerge das memórias de desejo agressivo e culpado, de um menino por sua mãe, mas também das memórias de sua dependência dela - uma dependência rememorada, no entanto, como a sedução de um menino burguês, austríaco, por uma mulher da classe trabalhadora tcheca, numa província do Império Austríaco que ainda se recuperava da revolução de 1848 (Id. ib.:64).

Depois de Swan, Jane Gallop fez uma análise sobre a importância da babá na cena analítica a partir da discussão de Catherine Clément e Hélène Cixous (1975) do caso Dora, observando que a figura da babá, ou governanta, não se esgota na identificação de Freud com uma babá ou criada neste caso, mas tem uma "relação estrutural, decisiva", com a psicanálise.

Em nenhum dos textos freudianos, a família esteve completamente fechada às questões da classe econômica. E o locus mais insistente dessa intrusão no círculo familiar (intrusão do simbólico no imaginário) é a criada/ governanta/babá. Como diz Cixous, "ela é o buraco na célula social" (Gallop, 1992:144). ${ }^{19}$

A análise de Cixous, retomada aqui por Gallop, é de que o que Freud não tolerou na sua relação com Dora foi ter sido dispensado por ela - como o seria uma governanta ou uma babá

\footnotetext{
${ }^{19}$ Como Ginzburg, Gallop também observa que muitos anos depois de ter supostamente abandonado a teoria da sedução, Freud faz menção a ela em 1931 (em Female sexuality, SE, vol.XXI): "A contribuição da higiene doméstica no iniciar [da atividade fálica], reflete-se na fantasia muito comum que torna a mãe ou a babá uma sedutora ... A sedução real é também bastante comum; ela é iniciada seja por outras crianças, ou por alguém que toma conta da criança, desejando acalmá-la, ou pô-la para dormir, ou para torná-la dependente de si". Citado por Gallop, com interpolação dela, ênfase adicional.
} 
- depois de um aviso prévio. ${ }^{20}$ "Nem Dora nem Freud podem tolerar a identificação com a babá seduzida e abandonada". Ser feminizado, para Freud, significaria aceitar o lugar das mulheres em circulação numa troca efetuada entre homens. Para Dora, significaria que, apesar de sua posição social, ela também era objeto dessa troca. No entanto, ao contrário do que diz Gallop, essa não é uma análise de Dora $e$ Freud - era Dora quem estava enraivecida "pelo fato de que tinha sido entregue ao Senhor K. em pagamento para que ele tolerasse as relações entre o pai dela $e$ a esposa dele". ${ }^{21}$

A intromissão das babás - ou das classes subalternas - nos lares burgueses vai ser retomada por Anne McClintock em 1995, desta feita acrescentando a variável raça ao universo pesquisado além de retomar a discussão da babá de Freud. Ela própria resume essa parte de sua pesquisa como a análise de "um dos atos de desaparecimento mais bem sucedidos da história moderna" - o da invisibilização do trabalho doméstico. ${ }^{22} \mathrm{E}$, como mostra, dava muito trabalho aparentar o lazer que supostamente as donas-de-casa burguesas ou de classe média ostentavam durante a época vitoriana. A excelente iconografia acumulada no capítulo dedicado ao trabalho doméstico quase dá conta, por si só, de expor seu argumento. A instigante história do casal S/M Arthur J. Munby e Hannah Culwick - sua esposa e sua empregada

\footnotetext{
${ }^{20} \mathrm{Na}$ sua análise, Freud interpreta que Dora não queria ser tratada como uma babá ou governanta - já que seu sedutor lhe fizera uma proposta usando os mesmos termos que usara para seduzir a babá dos filhos dele (Fragment of a case of hysteria:106). Assim, é interessante que tenha escolhido para ela o nome de uma babá.

${ }^{21}$ Fragment:34. A frase de Gallop é: "Dora e Freud descobriram um fragmento da estrutura geral que trinta anos depois Claude Lévi-Strauss chamará de estruturas elementares de parentesco, isto é, a troca de mulheres pelos homens". (p.132, ênfase adicional.) A observação é repetida na p.147. Sobre a resistência de Freud em identificar-se com posições femininas nos seus sonhos, ver também Anzieu (1989) e Swan (1974).

${ }^{22}$ Ver a tradução do capítulo que trata desse assunto - o cap. 3 - em cadernos pagu (20), 2003.
} 
A babá de Freud e outras babás

doméstica - quase fica em segundo plano nessa análise. Munby, que tinha o hábito de fotografar e desenhar mulheres das classes trabalhadoras - e que as enegrecia em seus desenhos - também tinha tido uma babá com essa origem de classe, chamada Hannah, e uma mãe delicada e distante. ${ }^{23}$ Seria difícil resumir aqui a complexa história acompanhada por McClintock, mas cabe lembrar que ela se vale de uma noção de Julia Kristeva, a de abjeção, para sublinhar que abjeto é "algo rejeitado, mas do qual não nos separamos" (McClintock, 1995:71). A noção, tributária da de Mary Douglas sobre poluição, poderia ter um melhor rendimento teórico no seu tratamento da relação gênero/raça, como veremos adiante. ${ }^{24}$ Propondo-se a articular, em sua análise, as categorias de gênero, raça, classe e sexualidade, a autora sugere que a figura liminar (evocada por Cixous e Gallop), sempre na porta entre a casa e a rua, a família e a perdição, da babá/governanta/criada mostra que a cisão vitoriana entre a mulher boa e a má - a santa e a puta - "teve origem, assim, não num arquétipo universal, mas na estrutura de classe da unidade doméstica" (Id. ib.:87). Era a "contradição cotidiana da unidade doméstica vitoriana - entre o poder mal e mal reprimido da trabalhadora doméstica assalariada e a relativa falta de poder da esposa não assalariada" que fundamentava essa duplicidade (Id. ib.:96). Assim, é uma pena que ela não tenha incluído o marcador idade na sua lista de categorias a serem consideradas, pois falha

\footnotetext{
${ }^{23}$ Não é o caso de repetir as coincidências dos nomes que aparecem no romance familiar freudiano, ou no universo das pacientes e analistas - coincidência que re-aparece aqui - mas vale a pena refletir sobre um desenho seu, no qual Munby aparece identificado com a delicada figura feminina das mulheres vitorianas, frente a uma grosseira, e escura, figura masculinizada de uma mulher trabalhadora, evocando a análise de Pierre Bourdieu sobre a "feminização" dos homens das classes dominantes, na sua análise, não análoga a uma "masculinização" das mulheres das classes trabalhadoras. Sobre o texto de Bourdieu a respeito da "dominação masculina", ver Corrêa, 1999.

${ }^{24}$ Agradeço a Camilo Albuquerque de Braz por ter me lembrado da influência de Mary Douglas sobre Julia Kristeva, que eu tinha "esquecido".
} 
inteiramente em apreender a perspectiva infantil da relação com a babá - a babá má em oposição à mãe boa, ainda que violenta.

Toda a sutileza demonstrada em sua análise das relações de classe na Inglaterra vitoriana é deixada de lado quando a autora se move para a África do Sul, acompanhando a trajetória da autora sul-africana Olive Schreiner (Id. ib.:cap.7). Por denunciar as estratégias domésticas de dominação das aias adultas - negras sobre as crianças, a ficção de Schreiner não recebe qualquer simpatia de McClintock. ${ }^{25}$ Assim como sua análise sobre a Inglaterra tem uma inflexão forte nas relações de classe, sua análise sobre a África do Sul é fortemente flexionada sobre a questão da cor, mais do que da raça. ${ }^{26}$ Retratando o conflito como se dando entre brancos e negros, a autora esquece com freqüência o que tinha anotado no início de seu trabalho - ao mostrar, por exemplo, que os irlandeses brancos eram não só socialmente enegrecidos como forma de desqualificação na

${ }^{25}$ Olive Schreiner (1855-1920), autodidata, e que também teve a experiência de trabalhar como babá, mal saída da adolescência, era filha de um casal de missionários - pai alemão e mãe inglesa - que foi exercer sua função na África do Sul e que enfrentaram uma pobreza extrema. Sua mãe a espancava brutalmente com frequência, o que pode estar na origem de sua luta contra as leis de açoitamento dos negros em seu país, e ela costumava fugir para um mundo de fantasia, devaneando de maneira semelhante às descritas para Anna O. e Anna Freud, desde muito pequena. Seu primeiro romance, The story of an African farm, publicado em 1883, primeiro sob um pseudônimo masculino, a tornou uma celebridade na Inglaterra vitoriana, granjeando-lhe a amizade de vários intelectuais - entre eles Edward Carpenter, Havelock Ellis e Eleanor Marx, dos quais foi muito próxima. Para retratos perceptivos dela, como feminista e ativista política, ver Doris Lessing (1973), Ruth Brandon (1990) e, especialmente, suas cartas (1988). McClintock se equivoca sobre vários pontos factuais de sua biografia e também ao dizer que as posições de Schreiner sobre a prostituição eram projeções de sua própria situação vulnerável e que ela não tinha conhecimento real sobre a vida das prostitutas - ver Brandon, 1990.

${ }^{26}$ Focalizar raça aqui, ao invés de se centrar na cor dos agentes, poderia ter significado tentar compreender a complexa articulação entre etnia, nacionalidade (no caso de Schreiner, a complicada relação entre um pai fraco, alemão, uma mãe inglesa, agressiva, e a nacionalidade, ainda não bem definida, sul-africana) e religião - tanto no caso dos nativos, como no dos agentes coloniais. 
A babá de Freud e outras babás

Inglaterra vitoriana, como também moralmente rebaixados. Raça torna-se, assim, sinônimo de cor, e todo o aspecto político do racismo se perde. ${ }^{27}$ Como ela própria observara, a cor por si só não basta para constituir-se num sinal de alteridade - no caso de Schreiner, a diferença é dada também pela idade: na sua ficção, trata-se da visão de uma menina sobre adultos opressores. $\mathrm{O}$ fato de que ela tenha se tornado uma ativista de oposição às políticas racistas de seu país é bem uma prova de sua lucidez, quando adulta, em relação à sua situação na infância. A autora perde também de vista que a luta anti-racista de Schreiner poderia ter sido produzida de maneira análoga à fascinação que Munby tinha pelas mulheres trabalhadoras - isto é, na convivência diária de ambos, na infância, com uma mulher trabalhadora e com mulheres negras. A noção de abjeção supõe alguma coisa que incorporamos na infância e da qual não podemos nos livrar: um fascínio ou uma repulsa.

Deixando de lado a frutífera utilização da psicanálise, feita no caso Munby/Culwick, e ao tratar Olive Schreiner como uma colonialista privilegiada, Mclintock apresenta, mas não analisa, as agressões sofridas por ela, sua auto-mutilação, seus devaneios e alegorias, "um obscuro trauma sexual", sua asma, que a acompanhou pela vida afora - e que a tornam tão semelhante às vienenses suas contemporâneas - para tratá-la como epígono de "uma condição colonial peculiar". Ao tomá-la como representativa da cultura colonial - que, afirma, citando outro autor, "não tem memória" - perde de vista sua condição humana e a trata como

${ }^{27} \mathrm{O}$ debate recente sobre a questão racial no Brasil, tanto na literatura acadêmica quanto na mídia, tem enfatizado à exaustão a idéia de que raça não existe - ver, por exemplo, a matéria da revista Veja de 6 de junho de 2007. O racismo, no entanto, persiste. Ver o belo trabalho de Sander Gilman (1993) sobre o racismo na Alemanha na época de Freud e, sobre o debate contemporâneo nos Estados Unidos, em boa parte reproduzido no Brasil, Sears e outros (2000). 
simples exemplo de "uma escritora colonialista". ${ }^{28}$ A menina humilhada e oprimida, porque branca, não pode beneficiar-se de qualquer simpatia pelo simples fato de que suas opressoras eram negras, e a complexa articulação proposta entre raça, classe, gênero e sexualidade se perde por se ter perdido uma dimensão fundamental da constituição da sexualidade - as experiências infantis. Foram tais experiências que ela, ao invés de levar para o divã, levou para sua ficção e para sua produção intelectual em geral. Não tendo sido judia, nem vivido em Viena, escapou ao rótulo que algumas de suas famosas contemporâneas receberam, a partir de "sintomas" muito semelhantes, que eram também sintomas da situação da mulher não satisfeita com as convenções sociais de seu tempo e que limitavam sua atuação. ${ }^{29}$ Reduzir essa constelação de experiências - na África, na Inglaterra, sua atuação intelectual e política, sua vida sempre fragilizada pela doença - a uma única causa, a situação colonial, é, no mínimo, empobrecer a trajetória de uma das mulheres mais interessantes da era vitoriana.

Aqui seria preciso uma longa digressão a respeito dos usos implícitos, nessa análise, da noção de cultura - no caso a "cultura colonial". Contento-me em citar a observação de Elisabeth Roudinesco (1989:176/7) sobre Jung que

sustentou que cada povo possuía uma mentalidade diferente da de seus vizinhos, e que, nessas condições, era preciso, pelo bem da ciência, construir uma psicologia adaptada à alma coletiva de cada povo.

${ }^{28}$ Para Freud e Breuer (1974:58), "As histéricas sofrem principalmente de lembranças" (ênfase original). Apesar de citar a análise de Jim Swam, McClintock também deixa de mostrar a analogia entre o caso de Olive e o caso de Freud em termos da aceitação de uma mãe boa (judia/inglesa) e uma babá má (católica, tcheca/ africana): a cisão vitoriana, resultado da estrutura da unidade doméstica, não se estende às colônias, nem leva em conta as disputas étnicas.

${ }^{29}$ É curioso que, tendo lutado também contra o anti-semitismo existente em seu país, Olive tenha parecido ao seu marido, que a re-encontrava depois de uma longa separação, no ano de sua morte, como "pequena e escura e judia" Brandon (1990:91). 
A babá de Freud e outras babás

É a alma dos povos. É a "coisa" coletiva, oculta e demoníaca pela qual o homem continua a ser sempre um sonâmbulo. ${ }^{30}$

\section{Guilhermina: as nossas babás}

Em 1912, Augusto dos Anjos (1884-1914) evocava numa poesia a experiência de Freud:

A minha ama de leite Guilhermina

Furtava as moedas que o Doutor me dava

[concluindo]

Furtaste a moeda só, mas eu, minha ama,

Eu furtei mais, porque furtei o peito

Que dava leite para a tua filha! ${ }^{31}$

Essa é das poucas referências ao fato de que as amas de leite negras tinham de abdicar de amamentar seus filhos - ou amamentá-los secundariamente - quando eram convocadas, ou alugadas, para amamentar as crianças brancas.

Numa análise análoga à de McClintock, Sandra Graham (1992) faz uma cuidadosa avaliação sobre a relação entre criadas -

${ }^{30}$ Desenvolvo em outro lugar uma reflexão sobre essa questão (Corrêa, 2007). Ainda que me pareça que Roudinesco interpreta de má vontade a trajetória junguiana, para contrastá-la com a de Freud, creio que ela aponta para uma conseqüência política importante dessa idéia de "diferentes povos/diferentes lógicas culturais" há muito presente na antropologia - e aqui implícita na análise da metrópole e das colônias.

${ }^{31}$ Ricordanza della mia gioventu, em Eu (1912), citado por Koutsoukos (2006). A foto do poeta paraibano aos dez anos, de botas e com um chicotinho nas mãos (convenção fotográfica de época?), evoca a foto de Munby usada por McClintock em seu livro - mas aí os sinais estão trocados: a elite de proprietários de terra estava em decadência e a poesia de Augusto dos Anjos era a expressão, individual e familiar, desse declínio e não de um "poder imperial". O poeta também parece ter sucumbido ao amor de uma jovem subalterna e a morte dela, talvez a mando de sua mãe, teria deixado uma impressão perene em sua poesia. Ver www.vidaslusofonas.pt/augusto_dos_anjos.htm 
as amas de leite, as mais bem pagas, entre elas - e patrões/patroas no Rio de Janeiro do final do século 19 e começo do século 20. Os dados que apresenta sobre o trabalho doméstico são semelhantes aos dados para a Europa e os Estados Unidos - uma maioria de mulheres dedicadas ao trabalho doméstico e, dentre elas, uma maioria de negras e solteiras. Graham também evoca figuras famosas da sociedade brasileira que tiveram vinculações com babás ou criadas - Machado de Assis, que deixou de pagar suas criadas, e Rui Barbosa, que reclamava por ter de usar uma babá para sua filha, já que a mulher não podia amamentar. ${ }^{32}$ Isto é, que aqui, como na Europa, a babá/criada era uma figura fundamental na manutenção da família. Tanto aqui, como lá, ela era também estigmatizada - a ênfase aqui sendo na possibilidade de transmissão de doenças, mais do que na transmissão de maus costumes, mas, nos dois casos, era de sua pobreza que advinha o perigo para as famílias. Também aqui as babás/criadas eram, às vezes, objeto do desejo dos patrões - mas nunca se menciona a possibilidade de sedução de crianças. É como se, no caso brasileiro, a cor fosse uma espécie de véu que cobria a pobreza perenemente invocada pelos reformadores sociais, seja no seu ataque aos cortiços, seja no ataque aos "miasmas" que provinham dos lugares habitados pelos pobres e ameaçavam os lares nos quais esses pobres (essas pobres, de início escravas) se infiltravam. ${ }^{33}$ Os matizes da pobreza, de fato, parecem importar menos do que a pobreza propriamente dita.

${ }^{32}$ Gilberto Freyre vai lembrar outras figuras históricas que também faziam referências às suas amas negras, como Silvio Romero e Joaquim Nabuco. Sobre Nabuco, diz ele: "O menino está mais satisfeito", escrevia a seu pai o amigo que o devia levar à Corte, "depois que eu lhe disse que a sua ama o acompanharia" (Freyre, 1984:354). Valeria a pena comparar essas reminiscências com as lembradas por McClintock, de figuras literárias e políticas da Inglaterra, para refletir sobre a importância das babás na vida de tantos personagens públicos do século dezenove.

${ }^{3}$ O trabalho de Graham, publicado originalmente em 1988, tinha o título em inglês de House and Street (A casa e a rua) e era declaradamente tributário da análise de Roberto Da Matta em Carnavais, malandros e heróis. 
A babá de Freud e outras babás

Num belo texto, no qual recupera a (pouca) bibliografia nacional sobre o tema da babá, Rita Laura Segato começa por apontar para as discussões, no contexto do debate sobre a abolição da escravidão, a respeito dos males "da contaminação $e$ da corrupção moral que a presença de negros na intimidade da casa senhorial estaria a introduzir" (Segato, 2006:5). ${ }^{34}$ Isto é, de negras, primeiro como amas de leite e, depois, como "amassecas", as babás que não aleitavam as crianças. ${ }^{35}$ Mostrando que a prevalência das mulheres no trabalho doméstico continua no nosso país a tradição evocada por Tilly e Scott na sua análise do período da revolução industrial, e por Graham para o Brasil do século 19, Segato cita a estatística oficial de 2006: 94,3\% dos trabalhadores/trabalhadoras domésticos são mulheres e 61,8\% deles, ou delas, são pretos ou pardos. Cita, em seguida, um

${ }^{34}$ A volta das amas de leite nos Estados Unidos - e sua introdução na China tem sido noticiada como um escândalo em jornais e revistas neste ano de 2007. Ver, por exemplo, na revista Isto é, de 2 de maio de 2007, a matéria na qual se noticia essa volta no cenário internacional e se afirma que no Brasil tal prática é proibida pelo Ministério da Saúde. Sobre a crescente presença de babás e empregadas domésticas "importadas" pelos Estados Unidos de países pobres, ver Ehrenreich e Hochschild, 2004.

${ }^{35}$ A ignorância sobre a situação das Américas, em geral, e sobre a instituição da escravidão em particular, faz com que McClintock diga, numa passagem em que está analisando a figura da babá na Inglaterra: "Certamente nenhuma outra cultura [como a britânica] dividiu a sexualidade feminina de maneira tão marcante segundo linhas de classe. As mulheres da classe trabalhadora eram vistas como biologicamente determinadas para a luxúria e o excesso; as mulheres das classes altas eram naturalmente indiferentes ao delírio da carne" (McClintock, 1995:86, ênfase adicional). Essa ignorância está vinculada a uma análise - como na discussão sobre Olive Schreiner - que exclui a escravidão do debate sobre o projeto colonial. As mulheres trabalhadoras, nas Américas, foram, antes da constituição de classes, as escravas (ver Graham, 1992). Ver também as reações das socialistas feministas a uma divisão semelhante na Rússia, em relação aos servos, por exemplo, na trajetória de Alexandra Kollontai, em Porter, 1980. As socialistas feministas, ou vice-versa, estão estranhamente ausentes de toda a análise de McClintock - particularmente no que se refere à vinculação de Olive Schreiner com os grupos socialistas de Londres - já que seu livro é uma cuidadosa desmontagem do ideal vitoriano da mulher frágil. 
registro, a partir de suas pesquisas com as religiões afro-brasileiras, nas quais Iemanjá seria a "mãe legítima" dos orixás - mãe biológica e mãe jurídica - e Oxum a "mãe de criação". Iemanjá seria o equivalente da mãe inglesa, citada antes: "mãe fria, hierárquica, distante $e$ indiferente". A autora não desenvolve a discussão sobre as qualidades de Oxum, mas recorre a registros iconográficos - como o da pintura que representa D. Pedro II no colo de sua ama, retrato a óleo atribuído a Debret, para registrar a importância da "mãe preta" na cena nacional. Recorre, depois, à outra análise, que mostra a transformação que as fotos de crianças e babás vão sofrendo entre 1862 e 1885.

Até aproximadamente 1880, as fotos captavam as crianças em composições na moda internacional da época; somente que, no Brasil, o típico quadro europeu da mãe segurando a criança junto ao rosto era substituída pela babá negra ocupando esse lugar. (...) Contudo, em torno de 1880, diz a autora, as composições revelam a progressiva intenção de ocultar a figura da ama negra que, ainda assim, necessariamente, continua a sustentar o bebê no seu colo para este poder ser fotografado, $e$ "as amas negras passam a existir nas fotografias como rastros: uma mão, um punho, até serem completamente banidas das imagens"; "a princípio mostrada com orgulho, de rosto inteiro, depois escondida, em segundo plano, desfocada e retocada, até ser completamente retirada do quadro nacional". ${ }^{36}$

Desapontando os leitores em relação à questão posta no título de seu trabalho - O Édipo brasileiro: a dupla negação de gênero e raça - a autora não desenvolve explicitamente a questão posta por Jim Swam: como é que a criança renega essa primeira experiência com a babá e a transfere para a mãe?

\footnotetext{
${ }^{36}$ Segato está citando o importante trabalho de Rafaela de Andrade Deiab, A memória afetiva da escravidão. Revista de História da Biblioteca Nacional, 1(4), outubro de 2005.
} 
A babá de Freud e outras babás

Ou não renega? É bem conhecida a proposta de Gilberto Freyre, ao analisar as relações entre a casa-grande e a senzala, afirmando, repetidamente, que era no convívio íntimo com as mães pretas que se desenvolvia a atração dos brancos, quando adultos, pelas negras, a marca da influência negra:

Da escrava ou sinhama que nos embalou. Que nos deu de mamar. Que nos deu de comer, ela própria amolengando na mão o bolão de comida. Da negra velha que nos contou as primeiras histórias de bicho e de mal-assombrado. $\mathrm{Da}$ mulata que nos tirou o primeiro bicho-de-pé de uma coceira tão boa. Da que nos iniciou no amor físico e nos transmitiu, ao ranger da cama-de-vento, a primeira sensação completa de homem (Freyre,1984:283).

Romantismos sociológicos à parte, Freyre, assim como Graham, traça um convincente retrato da intromissão das mulheres "de cor" na vida íntima da família brasileira branca, ou nem tanto, que teria resultado numa convivência também íntima entre brancos e negras no nosso país - ainda que raramente o vice-versa. Essa atração parece ter se cristalizado no mito brasileiro da "mulata gostosa", mas se, como sugeri em outro lugar (Corrêa, 1996), esse mito só pôde se constituir pela negação da negra preta, se a mãe preta dá lugar à mulata no imaginário brasileiro, isso sugere uma ambivalência entre as duas mães - a preta e a branca?

$\mathrm{O}$ que se nega e o que se incorpora dessa convivência afetiva na infância ainda está por ser analisado. Observando, no entanto, qualquer vizinhança de um bairro de classe média brasileira é possível notar que a convivência cotidiana de crianças brancas com babás negras não é apenas uma relação historicamente situada, mas está presente, até hoje, entre nós. Talvez seja possível avançar um pouco nesse questionamento sobre o que é negado e o que é incorporado dessa experiência afetiva infantil aproveitando a sugestão de McClintock sobre a duplicidade presente na unidade doméstica vitoriana - mas não mais pensando na distinção entre a mãe-boa e a babá-má (a santa 
e a puta) e sim na ambigüidade que a própria figura da ama de leite/babá/empregada doméstica encarnava no Brasil do século 19 e encarna ainda hoje.

Numa importante pesquisa sobre as fotografias de negros no Brasil, Sandra Koutsoukos (2006) dedica todo um capítulo às amas de leite, não só analisando inúmeras fotos de mulheres negras com crianças brancas ao colo, mas descrevendo a percepção social sobre essas mulheres, seja por parte de médicos, seja na ficção literária, seja na relação com as famílias. Nessa descrição, fica muito claro que a ama de leite expressava, na mesma pessoa, a duplicidade que vem sendo aqui apontada entre a mãe $e$ a babá. Ela é a figura explícita da dubiedade - podendo levar para dentro de casa todos os males de que porventura fosse portadora, ou toda a bondade e carinho esperados de alguém que entrega seu leite a uma criança que não é seu filho. Atacada na literatura ficcional ou médica, ou amorosamente retratada pelas famílias, a ama de leite corporificava uma figura ambígua, que podia ser boa e má ao mesmo tempo. ${ }^{37}$ Tal ambigüidade só seria resolvida com a decidida defesa, por parte dos médicos, do aleitamento materno e o conseqüente ataque às "amas mercenárias" - tanto negras como brancas, as que entravam no mercado com a imigração quando, então, sua figura se desdobraria em mãe-boa/ama-má. Com a persistência da utilização de mulheres pobres e mais escuras como babás, no entanto, a ambigüidade da relação da criança com sua babá retorna. ${ }^{38} \mathrm{E}$ será, também, reposta em

\footnotetext{
${ }^{37}$ Ver, por exemplo, o processo, referido por Koutsoukos (2006: 204), sobre uma ama de leite escrava que, ao saber que seu contrato para amamentar uma criança previa a sua libertação, passou a comportar-se de uma maneira diferente da esperada - o que levou a uma batalha jurídica entre os advogados dela e os de seus patrões: "querida" no início, foi em seguida perseguida por sua "ingratidão".

${ }^{38}$ Essa ambigüidade vai bem além da questão de diferença de cor: no caso das amas de leite, não era apenas porque eram negras - embora isto estivesse implícito no discurso - que elas eram rejeitadas, mas principalmente porque eram pobres, doentes e "mercenárias". Ver, em Ehrenreich e Hochschild (2004), várias análises de relações semelhantes às descritas por Koutsoukos para o Brasil, entre
} 
A babá de Freud e outras babás

outros termos, explicitando as ansiedades familiares em relação a essa figura que, quando vista de maneira benigna "é como se fizesse parte da família", e que, quando vista de maneira maligna, é alguém que traz os males do mundo para dentro de casa.

Numa discussão recente, durante uma reunião do grupo de trabalho da Comissão de Direitos Humanos do Senado, o padre Cláudio Antonio Delfino explicitava seus temores a respeito de babás lésbicas:

Tenho, por exemplo, uma sobrinha de um ano e dois meses. Imaginemos que colocássemos em casa alguém para ser babá dessa menina e viéssemos a descobrir com o tempo que a pessoa era homossexual e que tratasse de modo indevido a criança, que não tem como se defender. Agora, a pergunta que se faz é a seguinte: depois de descobrir isso, eu teria ou não o direito de dispensar essa pessoa porque estava tratando a criança de um modo que, para a família, seria inadequado?. ${ }^{39}$

Mais de um século depois de ter sido supostamente abandonada, a teoria da sedução continua a ser evocada para nomear o perigo (ou fantasma) que ronda as famílias - um fantasma (ou perigo) exterior - que renega, ou esquece, os perigos

as crianças brancas dos países ricos e suas babás pobres, e às vezes também mais escuras, na cena contemporânea. Tal como ocorria com o trabalho doméstico de mulheres pobres ou de escravas, no início da industrialização, que propiciava o "lazer" das classes abastadas, também hoje, como mostram as autoras nessa coletânea, esse trabalho, invisível, propicia a entrada de mulheres da classe média e alta do "primeiro mundo" no mercado profissional, às custas do trabalho de mulheres do "terceiro". Sobre as relações entre patroas e empregadas na cena brasileira contemporânea, ver Azerêdo (1988) e Kofes (2001).

${ }^{39}$ O grupo de trabalho debatia o Projeto de Lei 122/2006, que visa definir "crimes resultantes de discriminação ou preconceito de gênero, sexo, orientação sexual e identidade de gênero". Entre esses crimes, consta o da dispensa de empregados pelo empregador. O padre Delfino é o responsável pela Comissão Episcopal Pastoral para a Vida e a Família, da CNBB. Ver Simões (2007), a quem devo a citação, para o contexto do debate. 
interiores, postos em cena por vários analistas, há muito tempo. Essa é a cena que está posta em questão por esse debate: as ameaças às crianças vêm de fora ou vêm do interior das famílias ${ }^{40}$ No debate sobre a sedução de crianças, a primeira resposta parecia apontar para uma ameaça interna, reforçada pela bibliografia contemporânea sobre a questão do abuso sexual e do incesto. ${ }^{41}$ A segunda resposta apontava para os perigos exteriores - simbolizados pelas agressões de classe, etnia, raça, religião, etc. - que, entrando por assim dizer pela porta dos fundos, ameaçavam a suposta paz das famílias. Ou, como diz Gallop, a família está, afinal, aberta ou fechada ao mundo?

Talvez pensar sobre como as babás, de todas as procedências, e particularmente aquelas vindas de países pobres para os países ricos, ou das regiões mais pobres para as regiões mais ricas dos países pobres, têm sido importantes como a segunda mãe de crianças no mundo todo, possa nos ajudar a refletir sobre como os cruzamentos das categorias socialmente subordinadas (das quais as babás sempre fazem parte, seja como integrantes de grupos étnicos, migrantes, seja como socialmente subalternas, seja como meninas recrutadas para cuidar de bebês, ou crianças, de outras classes sociais - isto é, subordinadas pela sua posição de raça, classe ou idade) com as categorias subordinadas de idade (as crianças das quais elas cuidam), nos levem a refletir sobre a importância da infância para a nossa vida adulta - e sobre o fato, sobejamente enfatizado em qualquer uma

${ }^{40}$ Não sei se $O$ encontro marcado, romance de Fernando Sabino de 1956, foi dos primeiros romances urbanos a por em questão a importância do quarto da empregada para os jovens adolescentes do sexo masculino como um lugar de iniciação sexual, mas foi certamente uma observação que pôs a nu, para os homens e mulheres que o leram, uma situação bem familiar - que seria reencontrada nas novelas de televisão nos anos 2000. Uma história arquitetônica do quarto da empregada certamente teria um enorme valor sociológico.

${ }^{41}$ Mas ver a reflexão de Ian Hacking (1999) sobre o desenvolvimento da noção de abuso de crianças como uma exacerbação da sensibilidade contemporânea que nos impediria de ajudar uma criança desconhecida a tomar água num bebedouro num parque público, por exemplo. 
A babá de Freud e outras babás

das "novelas das oito", sobre como as famílias não estão imunes ao mundo que as cerca.

\section{A peste}

Li em algum lugar que, ao entrar no porto de Nova Iorque, em sua primeira viagem à América, Freud teria comentado com Jung: "eles não sabem que estamos lhes trazendo a peste". A peste, como metáfora de algo que é levado do exterior para o interior, certamente continua a se espalhar até hoje, no âmbito da releitura da história freudiana: há sempre uma carta, um depoimento, ou algum documento não mencionado antes, que mostram que as coisas não eram bem assim, que o que tinha sido mostrado não era tudo o que havia para ser mostrado, ou que o que foi mostrado não correspondia à análise feita. Isto é, que as fantasias sobre essa história fazem parte de uma análise sem fim, ou de uma análise interminável. ${ }^{42}$

Parece que o mesmo se passa com as babás/criadas/ governantas - toda a discussão acompanhada até aqui mostra uma certa unanimidade na análise das empregadas domésticas: são perigos do exterior (de fora para dentro, da rua para a casa, do público para o privado) os que põem em risco as relações familiares existentes. As babás/criadas, guardiãs de uma história que poucos conhecem, trazem para dentro de casa uma peste que, afinal, acaba se expressando de alguma maneira. A recente notícia do espancamento gratuito sofrido por uma empregada doméstica - e outras mulheres pobres - num ponto de ônibus, por rapazes de classe média no Rio de Janeiro, parece estar apontando para um problema maior do que o expresso nos faits-divers dos jornais, ou nos comentários indignados de editoriais e cartas de leitores: uma intersecção estrutural entre as classes neste país, historicamente presente há muito tempo e que remete, quem sabe, à questão de os jovens estarem tentando se desforrar, na

${ }^{42}$ Ver Borch-Jacobsen e Shamdasani, 2006. 
rua, da abjeção que incorporaram em casa. A abjeção sendo, ela própria, um conceito que expressa incorporação e expulsão - traz para dentro e põe para fora. Talvez nós, feministas, devêssemos nos dedicar mais a refletir sobre isso.

\section{Referências bibliográficas}

AHBEL-RAPPE, Karin. "I no longer believe": did Freud abandon the seduction theory? Journal of the American Psychoanalytic Association, 54/1, 2006.

ANDREAS-SAlomÉ, Lou/FreUd, Anna. À l'ombre du pére. Correspondance, 1919-1937. Paris, Hachette, 2006.

ANZIEU, Didier. A auto-análise de Freud e a descoberta da psicanálise. Porto Alegre, Artes Médicas, 1989.

AZERÊDO, Sandra. Relações entre empregadas e patroas: a interelação do racismo e sexismo. Psicologia e Sociedade 3(4), 1988.

Berthelsen, Detlef. Dia a dia com a família Freud. Depoimentos da governanta Paula Fichtl. Rio de Janeiro, Civilização Brasileira, 1996.

BORCH-JACOBSEN, Mikkel e SHAMDASANI, Sonu. Le dossier Freud. Enquête sur l'histoire de la psychanalyse. Paris, Les empêcheurs de penser rond, 2006.

BRANDON, Ruth. The new women and the old men. Love, sex and the woman question. N.Y./London, W.W. Norton \& Co., 1990.

ClÉMENT, Catherine e CIXOUS, Hélène. La jeune née. Paris, Union Généraled'Éditions, 1975.

CORRÊA, Mariza. III Relatório ao Projeto Temático "Gênero, corporalidades", Fapesp, 2007. . O sexo da dominação. Novos Estudos Cebrap (54), 1999.

. Sobre a invenção da mulata. cadernos pagu (6/7), Núcleo de Estudos de Gênero - Pagu/Unicamp, 1996.

CREED, Bárbara. "Little Hans" reconsidered: or "the tale of mother's terrifying widdler". In: The monstrous-feminine. Film, feminism, psychoanalysis. Londres/N.Y., Routledge, 1993.

DA MATTA, Roberto. Carnavais, malandros e heróis: para uma sociologia do dilema brasileiro. Rio de Janeiro, Zahar, 1981. 
A babá de Freud e outras babás

DE SALVo, Louise. Virginia Woolf. The impact of childhood sexual abuse on her life and work. Boston, Beacon Press, 1989.

EHRENREICH, Barbara e Arlie R.HOCHSCHILD. (eds.) Global woman. Nannies, maids, and sex workers in the new economy. N.Y., Henry Holt and Company, 2004.

FREUD, Anna. O ego e os mecanismos de defesa. Rio de Janeiro, Editora Civilização Brasileira, 1983.

FREUD, S. Analysis of a phobia in a five-year-old boy (1909), SE vol. X.

. Minhas teses sobre o papel da sexualidade na etiologia das neuroses (1906), SE vol.VII.

. Fragment of an analysis of a case of hysteria (1905). The Standard Edition of the Complete Psychological Works of Sigmund Freud. London, The Hogarth Press, vol. VII. . Três ensaios sobre a teoria da sexualidade(1905), SE vol.VII.

. Psychopathologia da vida cotidiana. Rio de Janeiro, Editora Guanabara, sdp.

FREUD, S. e BREUER, J. Studies on hysteria. London, Penguin Books, 1974.

FREYRE, Gilberto. Casa-grande \& senzala. Formação da família brasileira sob o regime da economia patriarcal. Rio de Janeiro, José Olympio editora, 1984 [1933].

GalloP, Jane. Keys to Dora, em The daughter's seduction. Feminism and Psychoanalysis. Ithaca, N.Y., Cornell University Press, 1992 [1982].

GILMAN, Sander. The case of Sigmund Freud. Medicine and identity at the fin de siècle. Baltimore, London, The Johns Hopkins University Press, 1993.

GINZBURG, Carlo. Freud, o homem dos lobos e os lobisomens. In: Mitos, emblemas, sinais. Morfologia e história. São Paulo, Companhia das Letras, 1989.

GooDY, Jack. On nannas and nannies. In: Comparative studies in kinship. London, Routledge, 1969.

GraHAM, Sandra. Proteção e obediência. Criadas e seus patrões no Rio de Janeiro - 1860-1910. São Paulo, Companhia das Letras, 1992. 
HACKING, Ian. Kind-making: the case of child abuse. In: The social construction of what?. Cambridge, Massachusetts, Harvard University Press, 1999.

KOFES, Suely. Mulher, mulheres. Identidade, diferença e desigualdade nas relações entre patroas e empregadas domésticas. Campinas, Editora da Unicamp, 2001.

KouTSOUKOS, Sandra Sofia Machado. No estúdio do fotógrafo. Representação e auto-representação de negros livres, forros $e$ escravos no Brasil da segunda metade do século XIX. Tese de Doutorado, Instituto de Artes, Unicamp, 2006.

LESSING, Doris. Afterword to The history of an African farm by Olive Schreiner. In: A small personal voice. Essays, reviews, interviews. N.Y., Alfred A. Knoft, 1973.

MASsON, Jeffrey M. Atentado à verdade. A supressão da teoria da sedução por Freud. Rio de Janeiro, Livraria José Olympio Editora, 1984.

(ed.) A correspondência completa de Sigmund Freud para Wilhelm Fliess, 1887-1904. Rio de Janeiro, Imago, 1986.

MCCLINTOCK, Anne. Imperial leather: race, gender and sexuality in the colonial contest. N.Y./London, Routledge, 1995.

Couro imperial. Raça, travestismo e o culto da domesticidade. cadernos pagu (20), Núcleo de Estudos de Gênero - Pagu/Unicamp, 2003.

MCLEER, Anne. Practical perfection? The nanny negotiates gender, class, and family contradictions in 1960s popular culture. NWSA Journal, 14 (2), 2002.

MEYER, Catherine. (org.) Le livre noir de la psychanalyse. Paris, les arènes, 2005.

PORTER, Cathy. Alexandra Kollontai. A biography. London, Virago, 1980.

ROUDINESCO, Elisabeth. História da Psicanálise na França. A batalha dos cem anos. Volume 1: 1885-1939. Rio de Janeiro, Jorge Zahar, 1989.

SCHREINER, Olive. Letters. Vol.1. Ed. Richard River. Cambridge, Oxford University Press, 1988. 
A babá de Freud e outras babás

SEARS, David O. et alii. (eds.) Racialized politics. The debate about racism in America. Chicago/London, The University of Chicago Press, 2000.

SEGATO, Rita Laura. O Édipo brasileiro: a dupla negação de gênero e raça. Série Antropologia (400), Departamento de Antropologia, Universidade de Brasília, 2006.

SIMÕES, Julio de Assis. III Relatório ao Projeto Temático "Gênero, corporalidades", Fapesp, 2007.

SwAN, Jim. Mater and Nannie: Freud's two mothers and the discovery of the Oedipus Complex. American Imago 31 (1), Spring, 1974.

TiLLY, Louise e SCOTT, Joan. Women, work \& family. N.Y., Holt, Rinehart and Winston, 1978.

VIEIRA, Yara Frateschi. Sob o ramo da bétula. Fernando Pessoa e o erotismo vitoriano. Campinas, Editora da Unicamp, 1989.

Young-BRUEHL, Elisabeth. Anna Freud. Uma biografia. Rio de Janeiro, Imago, 1992. 